\title{
PRESSURE DEPENDENCE OF DEFECT EMISSIONS AND THE APPEARANCE OF PRESSURE-INDUCED DEEP CENTERS IN CHALCOPYRITE ALLOYS $\mathrm{Ag}_{x} \mathrm{Cu}_{1-\mathrm{x}} \mathrm{GaS}_{2}$
}

\author{
In-Hwan Choi \\ Department of Physics, Chung-Ang University, Seoul, Korea \\ and \\ Peter Y. $\mathrm{Yu}^{(\mathrm{a})}$ \\ Department of Physics, University of California, Berkeley, \\ and \\ Materials Sciences Division, Lawrence Berkeley National Laboratory, \\ Berkeley, CA 94720.
}

\begin{abstract}
We present the pressure dependence of the defect emissions in the chalcopyrite alloy semiconductor $\mathrm{Ag}_{\mathrm{x}} \mathrm{Cu}_{1-\mathrm{x}} \mathrm{GaS}_{2}$ for values of the alloy concentration $\mathrm{x}$ varying between 0 and 1 . A large variation in the pressure coefficients of the different defect emissions with $\mathrm{x}$ was found. In one alloy concentration $\mathrm{x}=0.25$ deep levels were found to appear under pressure. Plausible explanations of our results have been proposed.
\end{abstract}

PACS:78.20.Hp; 78.30.Hv; 63.20.Kr

Substance Classification: S8.11

(a) email: PYYU@LBL.GOV; fax: 510-643-8497. 
Recently alloys of chalcopyrite semiconductors such as $\mathrm{CuGa}_{\mathrm{x}} \mathrm{In}_{1-\mathrm{x}} \mathrm{Se}_{2}$ have received attention for improving the performance of solar cells[1]. As a result, the effect of alloying on the electronic band structure and vibrational properties of several chalcopyrite alloy systems have been investigated[2-5]. However, the effect of alloying on the defect properties in chalcopyrite semiconductors is still largely unexplored[3]. It is now well-established that donors in alloys of zincblende-type semiconductors, like AlGaAs, exhibit a shallow-to-deep donor transformation as a function of both pressure and alloy concentration[6]. In view of the close relation between the chalcopyrite and the zincblende structures, it is interesting to ask whether this phenomenon can also occur in the chalcopyrite semiconductors. In this paper we have studied the pressure dependence of defect photoluminescence (PL) in $\mathrm{Ag}_{\mathrm{x}} \mathrm{Cu}_{1-\mathrm{x}} \mathrm{GaS}_{2}$ for several alloy compositions. While we did not see shallow-to-deep transformation as a function of alloy concentration, we observed signatures of such transformation as a function of pressure in the alloy $\mathrm{Ag}_{0.25} \mathrm{Cu}_{0.75} \mathrm{GaS}_{2}$. A lack of reliable band structure calculation in the $\mathrm{Ag}_{\mathrm{x}} \mathrm{Cu}_{1-\mathrm{x}} \mathrm{GaS}_{2}$ alloys precludes at present a definitive explanation of this result. However, qualitative explanations are proposed.

We have grown alloys of $\mathrm{Ag}_{\mathrm{x}} \mathrm{Cu}_{1-\mathrm{x}} \mathrm{GaS}_{2}$ with $\mathrm{x}=0.25,0.5$, and 0.75 with the horizontal Bridgman method. The samples were not intentionally doped. They have been characterized by x-ray diffraction and found to be single-phased and crystalline. Details of the properties of these samples 
have been presented elsewhere [5] and will not be reproduced here. The high pressure optical experiments were performed with the sample placed inside a standard gasketed diamond-anvil cell using a mixture of methanol and ethanol as the pressure medium. The pressure inside the cell was determined by the ruby fluorescence technique. The entire cell was cooled to $50 \mathrm{~K}$ in a closed-cycle $\mathrm{He}$ refrigerator. The photoluminescence measurement was excited by an $\mathrm{Ar}^{+}$laser, analyzed with a double spectrometer and detected with a photon counting system.

In Fig. 1 (a)-(c) we show a series of pressure dependent PL spectra in $\mathrm{Ag}_{\mathrm{x}} \mathrm{Cu}_{1-\mathrm{x}} \mathrm{GaS}_{2}$ alloys for $\mathrm{x}=0.25,0.5$ and 0.75 . When compared with the corresponding spectra in $\mathrm{AgGaS}_{2}$ and $\mathrm{CuGaS}_{2}$ samples grown under similar conditions [5] we notice similarities between the alloy PL spectra and those of $\mathrm{AgGaS}_{2}$ and $\mathrm{CuGaS}_{2}$. In all the samples either one or two defect emission peaks are observed. In $\mathrm{Ag}_{0.75} \mathrm{Cu}_{0.25} \mathrm{GaS}_{2}$ only one emission peak is observed as in $\mathrm{CuGaS}_{2}$. On the other hand, the $\mathrm{x}=0.25$ and 0. 5 samples show two PL peaks as in $\mathrm{AgGaS}_{2}$. The higher energy peak in both $\mathrm{AgGaS}_{2}$ and $\mathrm{CuGaS}_{2}$ has previously been labeled $\mathrm{B}$ [5]. It has been attributed to donor-acceptor pair recombination and has been found to follow the band gap as a function of alloy concentration[5]. The lower energy peak, labeled previously as $\mathrm{C}$, has been attributed to deep centers emission and its energy does not follow the band gap as a function of $x$ [5].

In Table 1 we list the pressure coefficients of the PL peaks B and $\mathrm{C}$ in $\mathrm{Ag}_{\mathrm{x}} \mathrm{Cu}_{1-\mathrm{x}} \mathrm{GaS}_{2}$ alloys. For comparison purpose we have included the 
corresponding pressure coefficients in both $\mathrm{AgGaS}_{2}$ and $\mathrm{CuGaS}_{2}$ and also the band gap $\left(E_{\mathrm{g}}\right)$ pressure coefficients measured in separate optical absorption experiments[8]. In the case of $\mathrm{Ag}_{0.25} \mathrm{Cu}_{0.75} \mathrm{GaS}_{2}$ the PL spectra shown in Fig. 1 (a) indicate that both $\mathrm{B}$ and $\mathrm{C}$ exhibit very striking changes at pressures around $4 \mathrm{GPa}$. Above $3 \mathrm{GPa}$. Peak $\mathrm{B}$ weakens in intensity and disappears while another peak (which is labeled PB in Fig. 1(a)) appears above $5 \mathrm{GPa}$. This new peaks is narrower and has completely different pressure dependence from the peak B observed at lower pressures. The peak $\mathrm{C}$ seems to split into three narrower peaks around $5 \mathrm{GPa}$. While they are not very well resolved at low pressure, they become stronger in intensity and become much better resolved at higher pressure. The broken curves in Fig. 1(a) show the three individual peaks while the solid curve is their sum. The experimental points are shown in open circles. These peaks have been labeled $\mathrm{PC}_{1}$ to $\mathrm{PC}_{3}$. One striking characteristics of these new peaks appearing under high pressure is their very small and negative pressure coefficients. The pressure coefficients of these new peaks are also listed in Table 1. Similar tendency of the peak $\mathrm{C}$ to show a negative pressure coefficient is found in the other two alloys with $\mathrm{x}=0.5$ and $\mathrm{x}=0.75$. However it is more difficult to decide in these alloys whether there are additional fine structures in peak $\mathrm{C}$.

In the pure compounds we have found that the pressure coefficient of the peak B to be larger than that of the band gap. This remains true in the alloys except for $x=0.75$. Unlike the case of $\mathrm{CuGa}_{\mathrm{x}} \mathrm{In}_{1-\mathrm{x}} \mathrm{Se}_{2}$ whose 
band gap pressure coefficient $\mathrm{dE}_{\mathrm{g}} / \mathrm{dP}$ varies linearly with $\mathrm{x}[4]$, the variation of $\mathrm{dE} / \mathrm{dP}$ in $\mathrm{Ag}_{\mathrm{x}} \mathrm{Cu}_{1-\mathrm{x}} \mathrm{GaS}_{2}$ with $\mathrm{x}$ is highly nonlinear as shown in Table 1 . However, the variation of the pressure coefficients of the defect emission peaks with $\mathrm{x}$ is even more nonlinear than that of the band gap. The only trend one can deduce from Table 1 is that the pressure coefficients of the defect emission B in the alloys are always smaller than those in the pure compounds.

So far there has been very little theoretical studies of the effect of alloying on the band structure and defect properties in chalcopyrite alloys. The only report known to us [3] deals with the alloy system: $\mathrm{CuGa}_{\mathrm{x}} \mathrm{In}_{1-}$ ${ }_{x} \mathrm{Se}_{2}$. In comparing the results in this alloy system with our results in $\mathrm{Ag}_{\mathrm{x}} \mathrm{Cu}_{1-\mathrm{x}} \mathrm{GaS}_{2}$ one has to keep in mind the important differences between the two systems. In the former alloy system, In is replaced by another nontransition metal ion Ga. As pointed out by Wei et al.[3] the main effect of this replacement on the band structure is to change the conduction band. The difference in electronegativity and ionic radii between In and $\mathrm{Ga}$ contributes to a rather large bowing parameter of $\sim 0.2 \mathrm{eV}$ in $\mathrm{CuGa}_{\mathrm{x}} \mathrm{In}_{1 \text { - }}$ ${ }_{x} \mathrm{Se}_{2}$ [3]. However, the perturbation on the $\mathrm{Cu} d$-bands is minimal. In the $\mathrm{Ag}_{\mathrm{x}} \mathrm{Cu}_{1-\mathrm{x}} \mathrm{GaS}_{2}$ system, $\mathrm{Cu}$ is replaced by another transition metal ion $\mathrm{Ag}$. In addition to their difference in electronegativity and ionic radii there is now significant difference in their $d$-bands. It is known that the valence bands in the chalcopyrites are strongly affected by the $p$ - $d$ hybridization[910]. Thus replacing $\mathrm{Cu}$ by $\mathrm{Ag}$ is expected to have strong effects on both 
the valence and conduction bands. One indication of this strong effect is the large bowing parameter of $\sim 0.8 \mathrm{eV}$ reported in $\mathrm{Ag}_{\mathrm{x}} \mathrm{Cu}_{1-\mathrm{x}} \mathrm{GaS}_{2}[5]$. The different dependence of $\mathrm{dE}_{\mathrm{g}} / \mathrm{dP}$ on $\mathrm{x}$ is obviously another indication.

We have noted previously that the pressure coefficient $\mathrm{dE}_{\mathrm{B}} / \mathrm{dP}$ of the defect emission peak $\mathrm{B}$ in the chalcopyrite semiconductors $\mathrm{AgGaS}_{2}$ and $\mathrm{CuGaS}_{2}$ are larger than the band gap coefficient $\mathrm{dE} / \mathrm{dP}$ as a result of $p$ - $d$ hybridization in the valence bands[10]. Increasing this hybridization has the effect of decreasing the pressure coefficients since the $d$-bands tend to be less sensitive to pressure than the $p$-bands. Perhaps the most dramatic demonstration of this effect is the large drop in both $\mathrm{dE}_{\mathrm{B}} / \mathrm{dP}$ and $\mathrm{dE}_{\mathrm{g}} / \mathrm{dP}$ when $25 \%$ of $\mathrm{Ag}$ is added to $\mathrm{CuGaS}_{2}$. An increase in $\mathrm{dE} / \mathrm{dP}$ is observed when $\mathrm{Cu}$ is added to $\mathrm{Ag}$ also the effect is less striking. The appearance of the new peaks $\mathrm{PB}$ and $\mathrm{PC}_{\mathrm{i}}(\mathrm{i}=1-3)$ under pressure in $\mathrm{Ag}_{0.25} \mathrm{Cu}_{0.75} \mathrm{GaS}_{2}$ may also be related to the change in hybridization with alloying. However, the fact that these new peaks have very small and negative pressure coefficients also suggest that the conduction bands are altered in a significant way under pressure so as to change the nature of the donor (or donors) involved in the emission peak. As noted earlier the donor involved in the peak B has been understood to be a shallow donor. However, the donor involved in the peak PB is most likely a deep donor since its pressure dependence is quite different from that of the band gap.

At first sight the behavior of the PL peak B under pressure is rather similar to the conversion of shallow donors in GaAs to deep donors known 
as the DX centers under pressure[6]. However this transformation in III-V semiconductors are known to result from the near degeneracy of their conduction band minima under pressure. The I-III-VI $\mathrm{VI}_{2}$ chalcopyrite semiconductors are more similar to the II-VI zincblende semiconductors (like $\mathrm{CdS}$ and $\mathrm{ZnSe}$ ) whose $\mathrm{X}$ conduction band minima are typically too high in energy above the $\Gamma$ minimum for pressure to induce a cross-over. A more likely scenario is the existence of pressure induced lowering of a resonance deep level into the band gap. Alloying has also been known to facilitate such crossing of resonant deep levels and the $\Gamma$ conduction band minimum and shallow donor levels. Examples of such crossings include $\mathrm{N}$ in $\mathrm{Ga}_{\mathrm{x}} \mathrm{As}_{1-\mathrm{x}} \mathrm{P}$ [12] and oxygen in GaN[13]. Thus we suggest that deep donor levels resonant with the conduction band may exist in $\operatorname{Ag}_{\mathrm{x}} \mathrm{Cu}_{1-\mathrm{x}} \mathrm{GaS}_{2}$ alloys. These deep donors can be lowered into the bandgap by pressure and this process is facilitated by alloying $\mathrm{Cu}$ with $\mathrm{Ag}$.

\section{Acknowledgments}

The work at Berkeley was supported by the Director, Office of Energy Research, Office of Basic Energy Sciences, Materials Sciences Division, of the US Department of Energy under Contract No. DE-AC0376SF00098. IHC also acknowledges a fellowship from the Korea Science and Engineering Foundation (KOSEF 981-0208-033-2). 
Table 1 Pressure coefficient of band gap $\left(\mathrm{E}_{\mathrm{g}}\right)$, defect emission peaks B, C, $\mathrm{PB}, \mathrm{PC}_{1}, \mathrm{PC}_{2}$ and $\mathrm{PC}_{3}$ in $\mathrm{Ag}_{\mathrm{x}} \mathrm{Cu}_{1-\mathrm{x}} \mathrm{GaS}_{2}$ compared with the pure compounds $\mathrm{AgGaS}_{2}$ and $\mathrm{CuGaS}_{2}$. All units are in $\mathrm{meV} / \mathrm{GPa}$.

\begin{tabular}{|l|l|l|l|l|l|}
\hline \multirow{2}{*}{ Peak } & \multirow{2}{*}{$\mathrm{AgGaS}_{2}$} & \multicolumn{3}{|c|}{$\mathrm{Ag}_{\mathrm{x}} \mathrm{Cu}_{1-\mathrm{x}} \mathrm{GaS}_{2}$} & \multirow{2}{*}{$\mathrm{CuGaS}_{2}$} \\
\cline { 3 - 5 } & & $\mathrm{x}=0.75$ & $\mathrm{x}=0.5$ & $\mathrm{x}=0.25$ & \\
\hline $\begin{array}{l}\mathrm{E}_{\mathrm{g}}(<77 \\
\mathrm{K})\end{array}$ & $37-40.5$ & 43 & 36 & 33 & 42 \\
\hline $\mathrm{B}$ & 58 & 38 & 42 & 38 & 67 \\
\hline $\mathrm{C}$ & 41 & & & 31 & 24 \\
\hline $\mathrm{PB}$ & & & & $\sim 0$ & \\
\hline $\mathrm{PC}_{1}$ & & & & -2 & \\
\hline $\mathrm{PC}_{2}$ & & & & -4 & \\
\hline $\mathrm{PC}_{3}$ & & & & -1 & \\
\hline
\end{tabular}




\section{Figure Captions}

Fig. 1 The photoluminescence spectra in the alloy (a) $\mathrm{Ag}_{0.25} \mathrm{Cu}_{0.75} \mathrm{GaS}_{2}$,

(b) $\mathrm{Ag}_{0.5} \mathrm{Cu}_{0.5} \mathrm{GaS}_{2}$ and (c) $\mathrm{Ag}_{0.75} \mathrm{Cu}_{0.25} \mathrm{GaS}_{2}$ at $\mathrm{T}=50 \mathrm{~K}$ for several different pressures. In case of the high pressure spectra in (a) the broken curves represents the deconvolution of the peak $\mathrm{C}$ into three peaks denoted by the vertical arrows. The solid curve is their sum while the experimental points are shown as open circles. 


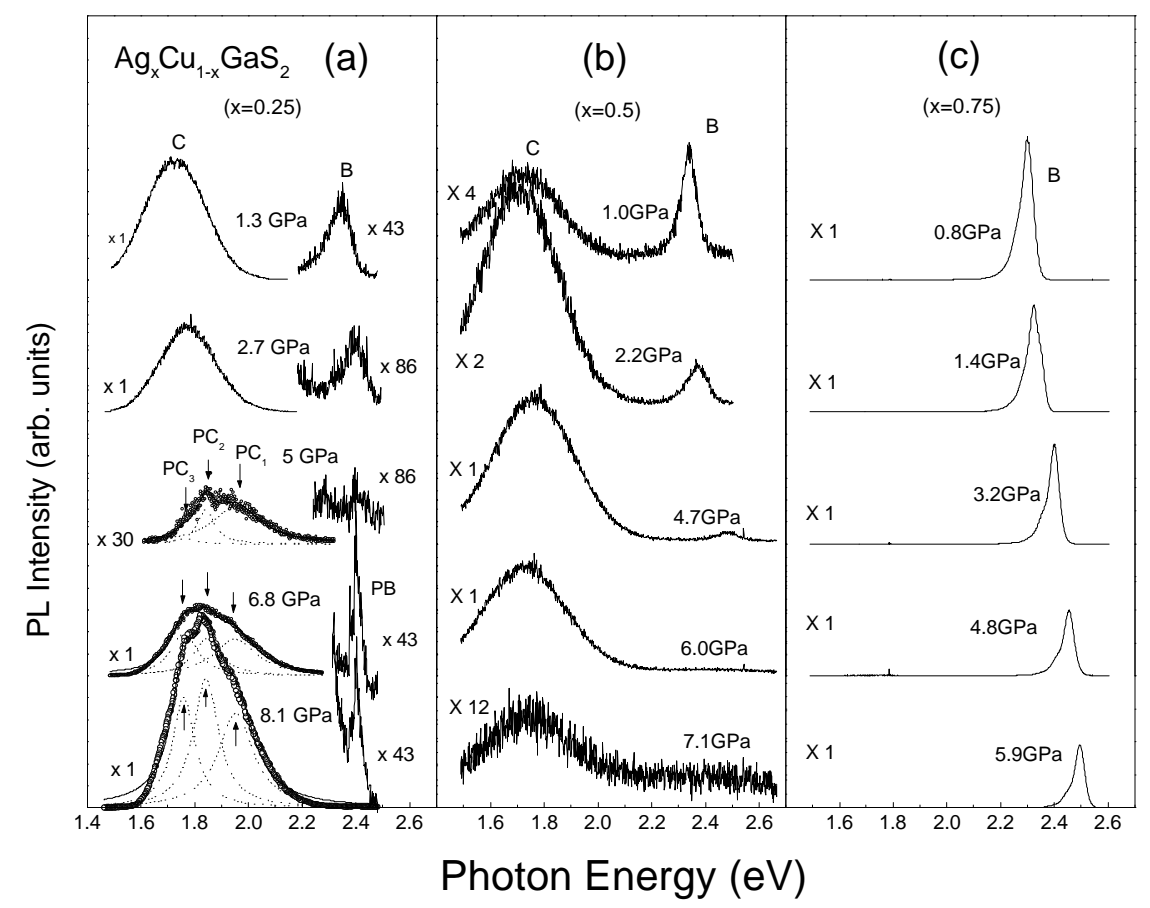

Fig. 1 


\section{REFERENCES}

[1] James R. Sites, and Xiaoxiang Liu, Solar Energy Materials \& Solar Cells, 41/42, 373 (1996).

[2] Zunger, A and Su-Huai Wei, AIP Conference Proceedings, (no.353), (13th NREL Photovoltaics Program Review, Lakewood, CO, USA, 16-19 May 1995.) AIP, 1996. p.155-60.

[3] S. H. Wei,S. B. Zhang and A. Zunger, Appl. Phys. Lett. 72, 3199 (1998).

[4] In-Hwan Choi and Peter Y. Yu, Phys. Stat. Solidi(b)211, 51(1999).

[5] In-Hwan Choi, Sung-Hwan Eom and P. Y. Yu, J. Appl. Phys. 87, 3815 (2000).

[6] See, for example, review paper by Ming-fu Li and Peter Y. Yu, in Semiconductors and Semimetals, Vol. 54a, edited by T. Suski and W. Paul(Academic Press, New York, 1998) p.457.

[7] Preliminary results have been presented in In-Hwan Choi, Sung-Hwan Eom and P. Y. Yu, Phys. Rev.B 61, 4689 (2000).

[8] In-Hwan Choi and Peter Y. Yu, Phys. Stat. Solidi(b)211, 143 (1999).

[9] J. E. Jaffe and A. Zunger, Phys. Rev. B 29, 1882 (1884).

[10] In-Hwan Choi and Peter Y. Yu,. Phys Rev B 55, 9642 (1997).

[12] D. J. Wolford, J. A. Bradley, K. Fry, J. Thompson, in Physics of Semiconductors 1984, ed. By J. D. Chadi and W. A. Harrison (Springer, New York, 1984) p.627. 
[13] C. Wetzel, T. Suski, J. W. Ager, E. R. Weber, E. E. Haller, S. Fischer, B. K. Meyer, R.J. Molnar, and P. Perlin, Phy. Rev. Lett. 78, 3923 (1997). 